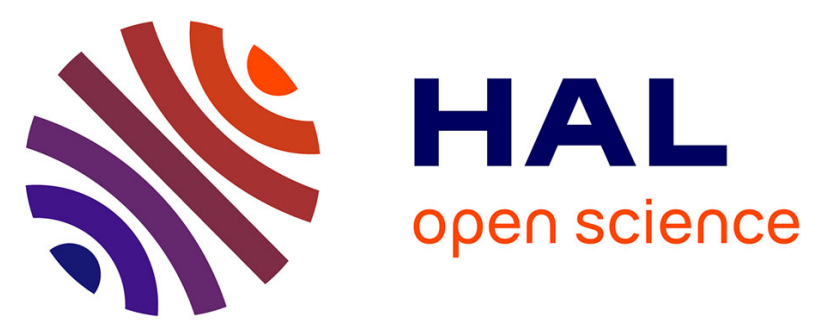

\title{
Retrospective analysis of tree architecture in silver fir (Abies alba Mill.): ontogenetic trends and responses to environmental variability
}

Olivier Taugourdeau, Jean Dauzat, Sebastien Griffon, Sylvie-Annabel Sabatier, Yves Caraglio, Daniel Barthélémy

\section{To cite this version:}

Olivier Taugourdeau, Jean Dauzat, Sebastien Griffon, Sylvie-Annabel Sabatier, Yves Caraglio, et al.. Retrospective analysis of tree architecture in silver fir (Abies alba Mill.): ontogenetic trends and responses to environmental variability. Annals of Forest Science, 2012, 69 (6), pp.713-721. 10.1007/s13595-012-0188-1. hal-00930838

\section{HAL Id: hal-00930838 https://hal.science/hal-00930838}

Submitted on 1 Jan 2012

HAL is a multi-disciplinary open access archive for the deposit and dissemination of scientific research documents, whether they are published or not. The documents may come from teaching and research institutions in France or abroad, or from public or private research centers.
L'archive ouverte pluridisciplinaire HAL, est destinée au dépôt et à la diffusion de documents scientifiques de niveau recherche, publiés ou non, émanant des établissements d'enseignement et de recherche français ou étrangers, des laboratoires publics ou privés. 


\title{
Retrospective analysis of tree architecture in silver fir (Abies alba Mill.): ontogenetic trends and responses to environmental variability
}

\author{
Olivier Taugourdeau • Jean Dauzat • Sébastien Griffon • \\ Sylvie Sabatier • Yves Caraglio • Daniel Barthélémy
}

Received: 15 October 2011 / Accepted: 26 January 2012 /Published online: 14 March 2012

(C) INRA / Springer-Verlag France 2012

\begin{abstract}
- Context Understanding the effects of exogenous factors on tree development is of major importance in the current context of global change. Assessing the structure development of trees is difficult given that they are large and complex organisms with lifespan of several decades.

- Aims We used a retrospective analysis to derive the ontogenetic trends in silver fir development and assess the effects of climate or light environment on tree architecture. - Methods Thanks to the identification of relevant growth markers (bud cataphylls and pseudo-whorl branches), a retrospective analysis allowed to record annual shoot extension and to date them on silver firs of various sizes under different environmental conditions.

- Results The length of successive annual shoots located on different axes clearly show gradual trends related to the physiological age of meristems. Within- and between-tree
\end{abstract}

Handling Editor: Gilbert Aussenac

Contribution of the co-authors Article writing: OT, JD, SS, YC; analysis: OT, software development: SG, supervision: JD, SS, YC, and DB

\author{
O. Taugourdeau $(\bowtie)$ \\ Université Montpellier 2, UMR AMAP, \\ Montpellier 34000, France \\ e-mail: o.taugourdeau@gmail.com \\ J. Dauzat $\cdot$ S. Griffon $\cdot$ S. Sabatier $\cdot$ Y. Caraglio \\ CIRAD, UMR AMAP, \\ Montpellier 34000, France \\ D. Barthélémy \\ INRA, UMR AMAP, \\ Montpellier 34000, France \\ D. Barthélémy \\ CIRAD, DIRBIOS, \\ Montpellier 34000, France
}

variations are noted due to the plasticity of development and growth induced by light environment and climate.

- Conclusion Retrospective analysis is an efficient method for getting information on the history of trees architecture and subsequently to relate it to environmental factors.

Keywords Morphological markers - A posteriori approach · Tree development $\cdot$ Phenotypic plasticity $\cdot$ Morphogenetic gradient

\section{Introduction}

Tree growth depends on many factors such as soil fertility, climatic events and inter-tree competition, and understanding the individual growth strategy and combined effects of these factors is of major importance for foresters and ecologists (Schenk 1996; Kelty 2006), particularly in the current context of global change. Unfortunately, the data needed to investigate how these factors act on tree development are difficult to collect given that tree development regularly spans several decades. Many studies of tree growth over time are therefore conducted in forest permanent plots where regular observations are used to monitor tree mortality (Richardson et al. 2009) and growth, but this approach is time consuming and costly. Also, such plots are limited in number and therefore do not fully reflect tree growth variability (Bontemps et al. 2009).

This problem can be avoided by using the current structure of the tree to retrieve its past history. Also, given that trees have a long lifespan, they are often used as markers of environmental conditions. Trees themselves, and especially wood, may therefore be considered as time recorders, dendrochronology studies have for many years been using this property to retrieve data on past growth (i.e. diameter 
increment) and interpret climatic trends and local or particular climatic events (Schweingruber 1996), forest history (gap, fire (Everett 2008), competition (Linares et al. 2010)) or recurrent biological phenomena (natural trauma, (Stoffel and Bollschweiler 2008), masting (Drobyshev et al. 2010)). Dendrochronology is also used to draw data from permanent plots for purpose of precise inter-annual variability analyses (Metsaranta and Lieffers 2009; Dulamsuren et al. 2011; Saulnier et al. 2011).

Stem analysis is a destructive approach used by foresters to assess the past dynamics of tree height. This analysis is based on counting of the number of rings at different heights along the stem. It basically reveals at what age the tree reached a given height. This information can then be used to interpolate main stem annual increments. The quality of these interpolations is greatly dependent upon sampling density along the stem (Dyer and Bailey 1987).

Alternatively, an accurate estimation of stem growth can be obtained by observing external growth markers: 'growth markers' are left each year between successive annual shoots in most (at least temperate) tree species (Barthélémy and Caraglio 2007). These growth markers generally remain visible for several years and can therefore be used to date plant structures. Observations made in a given year can therefore be used to reconstitute a tree's structure over several years in the past. This so-called retrospective reading of plant structure can be a powerful alternative to diachronic growth observations in permanent plots.

Retrospective reading mainly yields information on changes in annual shoot length along the trunk and branches. The number of lateral branches per annual shoot is another useful indicator of the tree's local vigour. These variables can be used to analyse the ontogenetic trends of tree development over time (Heuret et al. 2006). Alternatively, the effects of climatic events such as drought can be analysed by comparing growth variables for structures that developed at the same time (Chaubert-Pereira et al. 2009). Also, the vigour of individual trees can be compared in order to assess the impact of different growing conditions (Taugourdeau et al. 2011).

The purpose of this paper is to illustrate how the retrospective reading method can be used to (1) derive ontogenic trends in tree development, (2) evaluate the effect of climate on shoot growth within the crown, and (3) compare tree development with contrasted access to light.

Silver fir (Abies alba Mill.) was chosen as a model species for this study. Although a few retrospective analyses have already been conducted on silver fir (e.g. Robakowski et al. 2004), none provided a really clear methodology. Also, the Mediterranean region corresponds to the southern limit of this species and these Mediterranean populations are very sensitive to climate (Cailleret and Davi 2010).

\section{Material and methods}

\subsection{Growth markers and dating}

Annual stem growth in species originating from temperate areas takes place in one or more successive extension phases. The portion of leafy axis established during a continuous extension phase corresponds to a growth unit (Hallé and Martin 1968) and the portion of a leafy axis built up over a single growth year corresponds to an annual shoot (Barthélémy and Caraglio 2007). When considering the young axes of $A$. alba, winter growth stops are marked by a ring of cataphylls (i.e. scale leaves) that protect stem apical meristem and embryonic leaves and constitute the winter bud (Fig. 1a).

In silver fir, the main branches develop 1 year after extension of the bearing shoot (i.e. they are 1 year delayed) and are located at the sub-apical part of the annual shoots (Fig. 1a). They form branch pseudo-whorls (or 'branch tiers'). Unless $A$. alba suffers damage, or is in an early juvenile stage, it generally forms at least one branch every year (Edelin 1977). When cataphylls fall, branch tiers can be used to identify annual shoot limits (Fig. 1b-e). Branch insertions remain clearly visible after self-pruning (Fig. 1c) and branch scars may be visible down to the trunk base (Fig. 1d). When destructive measurements are made, wood ring numbers (Fig. 1f) can be used to confirm the number of annual shoot delimitations.

Annual shoot dating starts with current terminal annual shoots (Fig. 2) and moves downwards to the oldest shoots, with growth markers being used to date most of the plant's structures. Iterative branch development can also be used to compare dates between branches and thus confirm annual shoot dating since all paths from a given point to current year shoots must have the same number of annual shoots (Fig. 2b). If the base of the trunk allows for clear annual shoot delimitation (Fig. 2c), the year of tree birth can be accurately established. However, bark production in older trees may gradually erase external markers and can thus prevent clear birth dating (Fig. 1c-d). A rough estimation can nevertheless be made in such situations since each branch tier corresponds to an annual shoot limit. More precise birth date estimations need destructive measurements and the counting of tree stump rings.

If the apex of the stem dies, a lateral meristem or an existing branch may establish a new stem, at least 1 year later. This type of trauma can be clearly identified by inspecting external markers. In some cases, buds do not break during next-year spring but remain alive and break later. These two events are detectable when annual shoots are inter-dated. The principle of inter-dating consists to compare the estimated ages of different neighbouring annuals shoots at a given location in the tree. Given that main 

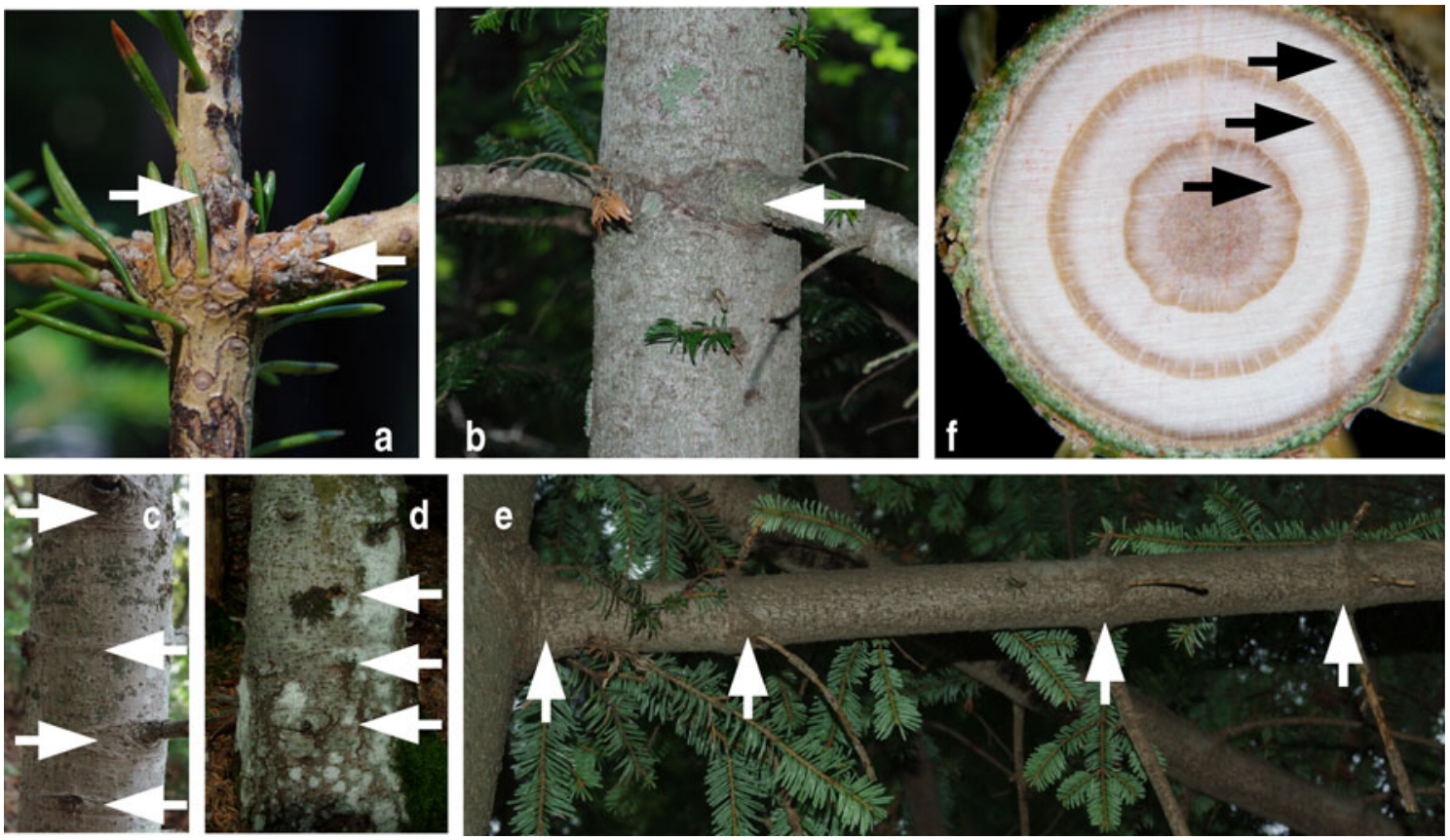

Fig. 1 Morphological markers resulting from growth in A. alba. a Winter bud cataphylls associated with short internodes mark the winter halt to growth (left arrow) on a young shoot, associated with a subapical branch pseudo-whorl (right arrow). b Successive annual shoot delimited by a branch tier on living crown in an adult tree. $\mathbf{c}$ Successive annual

branches develop 1 year after extension of the bearing shoot in fir trees, the stem portion must normally be 1 year older than the branch. If the difference is more than 1 year this indicates that the set-up of the branch was delayed. Interdating of several structures are often required when there is shoots delimited by dead branch tiers below living crown. d Successive annual shoots delimited by thinned scars at trunk base in an adult tree. $\mathbf{e}$ Successive annual shoots delimited by a twig tier on an old branch. $f$ Annual ring delimitation on a young axis transversal section

no visible marker of delayed bud break. In silver fir, this event appears mainly on frail axes.

As trunk secondary growth gradually includes the proximal part of each branch (Fig. 1e), its length is underestimated. This bias is corrected by adding half the diameter of
Fig. 2 Growth year

determination in A. alba. $\mathbf{a}$ and $\mathbf{b}$

Successive annual shoot

delimitation and year

determination based on branch tiers and inter-annual growth

limits along the main stem (a) or branches (b). c An exhaustive retrospective analysis provides an age determination in a 3-yearold sapling
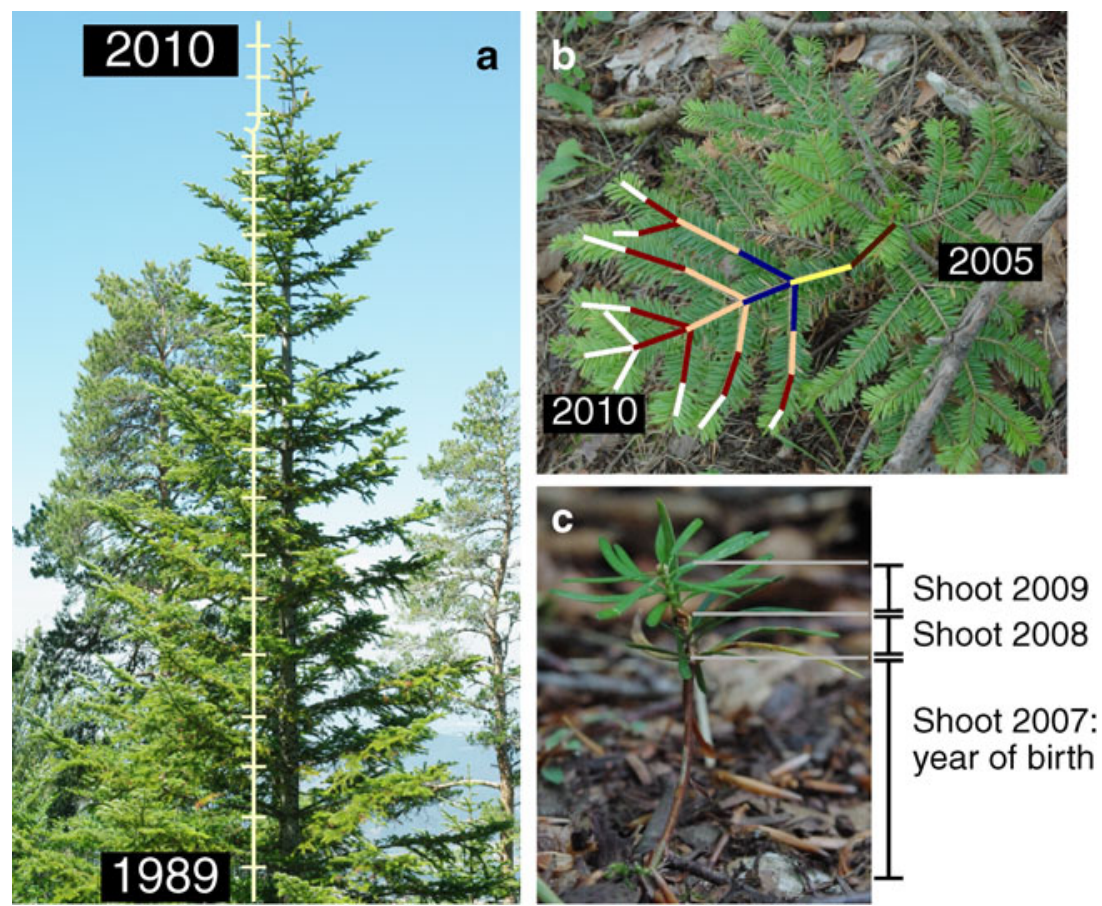
the bearer trunk annual shoot to the first annual shoot length measured.

\subsection{Data handling}

When measurements are made on different parts of a plant for purposes of analysing its structure (architectural organisation and axis differentiation concept, see Barthélémy and Caraglio 2007), it is useful to locate the plant entities observed within the tree's topological structure. Dedicated formalism, called Multi-scale Tree Graph (or MTG) has been developed to code the topological position of plant entities at different scales (Rey et al. 1997; Godin and Caraglio 1998).

In our study, we used Xplo (http://amapstudio.cirad.fr/) for data explorations and extractions. This software is fully compatible with the MTG data structure and provides a user-friendly method of exploring the MTG database and checking hypotheses on plant development. Specific data can be extracted with criteria combinations into tables and graphs. Simple analytical functions can be launched directly or data can be exported to external tools such as VPlant (Pradal et al. 2008) or R for more specific analyses.

\subsection{Dataset}

Silver firs were sampled in natural populations on the north

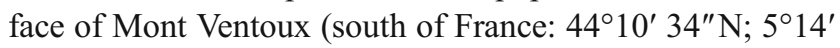
$06^{\prime \prime} \mathrm{E}$ ). Mont Ventoux is characterised by a typical Mediterranean mountain climate with a dry, warm summer and a cold winter (Cailleret and Davi 2010). Monthly, seasonal and annual rainfall variations and daily temperature are given in Fig. 3. The north face is characterised by a clear thermal gradient $\left(-0.7^{\circ} \mathrm{C} / 100 \mathrm{~m}\right.$ of elevation) but a low rainfall gradient $(+14 \mathrm{~mm} / 100 \mathrm{~m}$ of elevation), see Cailleret 2011 for details. Juvenile trees of different sizes (less than $3 \mathrm{~m}$ ) were sampled in populations at three different elevations (three at 1,150, three at 1,250, and five at $1,350 \mathrm{~m}$ ) noted N2, N3, and N4. Juvenile trees were sampled in two contrasting light environments: a closed environment, ranging from $7 \%$ to $9.8 \%$ canopy openness, and a clear environment, ranging from $26.4 \%$ to $53.3 \%$ canopy openness. Gap light analyzer software (GLA2, Frazer et al. 1999) was used to compute canopy openness from hemispherical photographs taken at the top of each tree. The light environment was estimated in 2009 (i.e. last year of growth) and was assumed to be representative of the tree's light environment over a number of years. One adult canopy tree was also sampled at the $1,150 \mathrm{~m}$ elevation.

Axes of branching order 2 and 3 were measured on the adult tree and one $2.2 \mathrm{~m}$ juvenile tree. Results presented here are subsamples of 11 and seven secondary axes for the adult and juvenile trees respectively and two tertiary axes for both.

\subsection{Crown dynamic reconstruction}

Crown development dynamics were inferred from the identification of growth years of the trunk and branches on the adult and juvenile tree. The crown-shape development over time was represented with hulls fitting the size of sampled branches along the trunk. This a posteriori reconstruction made two assumptions: (1) branches grow in a horizontal plane and (2) the branches measured are representative of crown dynamics.

One hull every 5 years was inferred in order to highlight developmental trends. For both trees, crown dynamics inference was limited by branch thinning under the actual living crown. Thus, the lower limits of past crown hull were not well defined.

\section{Results}

\subsection{Tree development}

The retrospective analysis of the adult tree, based on external markers, identified at least 57 annual shoots dating back to 1953, (Fig. 4). But 93 tree rings were counted on the stump (birth date: 1917). This difference is due to the fact that external markers had been deleted and the tree was devoid of living branches over the first $50 \mathrm{~cm}$ of the trunk (Fig. 1d). External annual shoot limits were clearly visible above this lower part of adult trees and all shoot limits were clearly visible in the juvenile tree.

Successive annual shoots on the trunk (Fig. 4) were between 1 and $49 \mathrm{~cm}$ in length for the adult tree and between 1 and $35 \mathrm{~cm}$ in length for the juvenile tree. All measured branches and twigs (Fig. 4) showed a general decrease in annual shoot length over time. This decrease was also visible at the crown hull dynamics scale (Fig. 4).

\subsection{Within- and between-tree variations in sensitivity to climate}

Annual shoot length trends (Fig. 5) showed inter-annual variations with an overall decrease between 2000 and 2006. Synchronous fluctuations may be interpreted as a global effect (e.g. interannual climatic variations) whereas asynchronous fluctuations may be interpreted as local effects (e.g. light variations). This decrease was related to organ size: trunk, branch and twig in decreasing order. Each trend was then normalised (relative to the highest value in each sub-dataset) such that they could be compared without any size effect (Fig. 5). Relative trends showed a similar 
Fig. 3 Meteorological data provided by a closed

MeteoFrance station (elevation $1445 \mathrm{~m}$ ), top monthly average of daily temperatures ( $\max , \min$ and mean) and sum of rainfall for the period 1993-2010; bottom annual and summer (June to August with dashed line) mean daily temperature and annual sum of rainfall broken down into three periods: summer months (June to August in dark grey), spring months (April and May in medium grey) and other months (January to March and

September to December in light grey). The three periods are also given in the top figure
Monthly average on the period 1993-2010

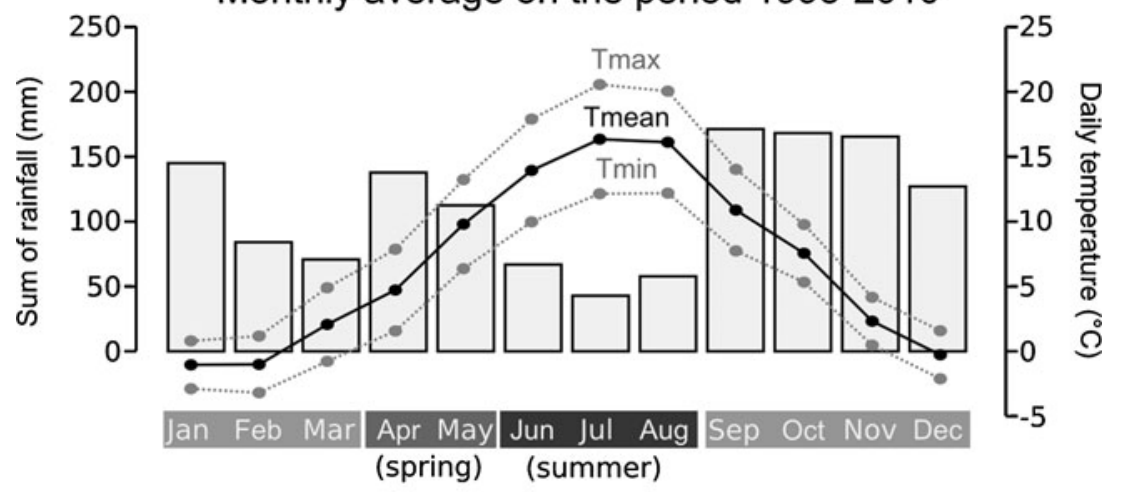

Annual and seasonal variations

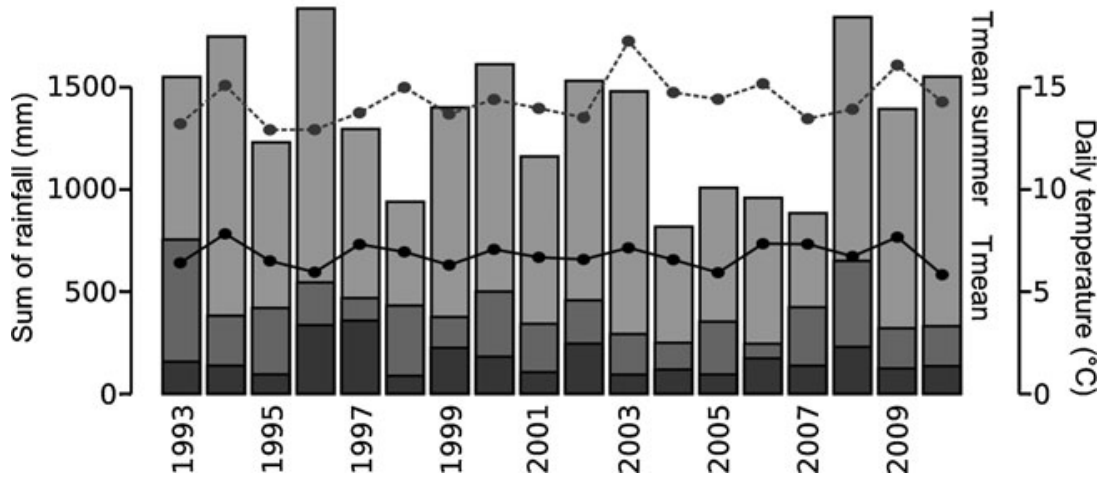

pattern of fluctuations: a similar decrease between 2000 and 2006 followed by a slight increase. Some axes in the lower part of the crown showed gaps in their trends, corresponding to axes relay or delayed bud development.
Trunk annual shoot length in one adult tree was associated with trunk annual shoot length in two juvenile trees of contrasting heights (Fig. 6). Each trend was then normalised (relative to the highest value in each sub-dataset) such that
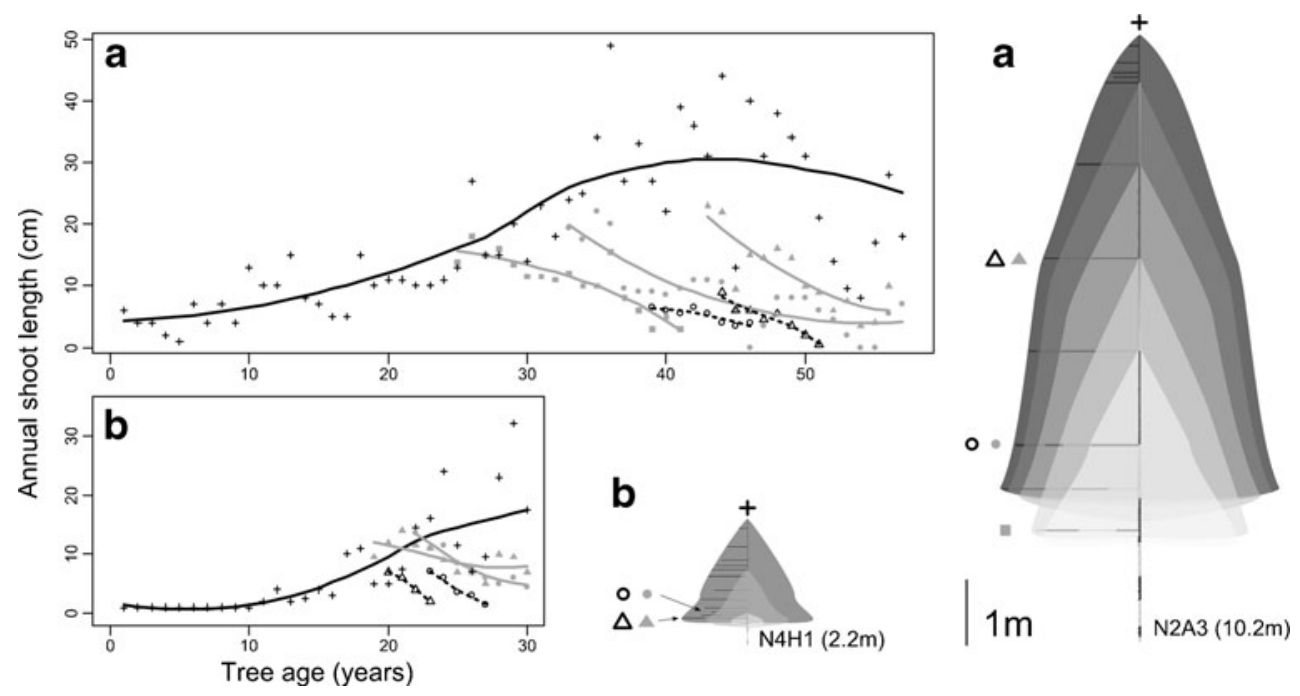

Fig. 4 Trunk, branches and crown growth. a Development of an adult tree: annual shoot length trends are given for the trunk (crosses and black line), three branches (triangles, points, squares and grey lines) and two twigs (empty circles, empty triangles and dashed lines). Axis positions within the crown are given in the adult crown scheme. b
Development of a juvenile tree: annual shoot length trends are given for the trunk (crosses and black line), two old branches (triangles, points and grey lines) and two twigs (empty circles, empty triangles and dashed lines). Local polynomial regressions were used to smooth the observed trends 

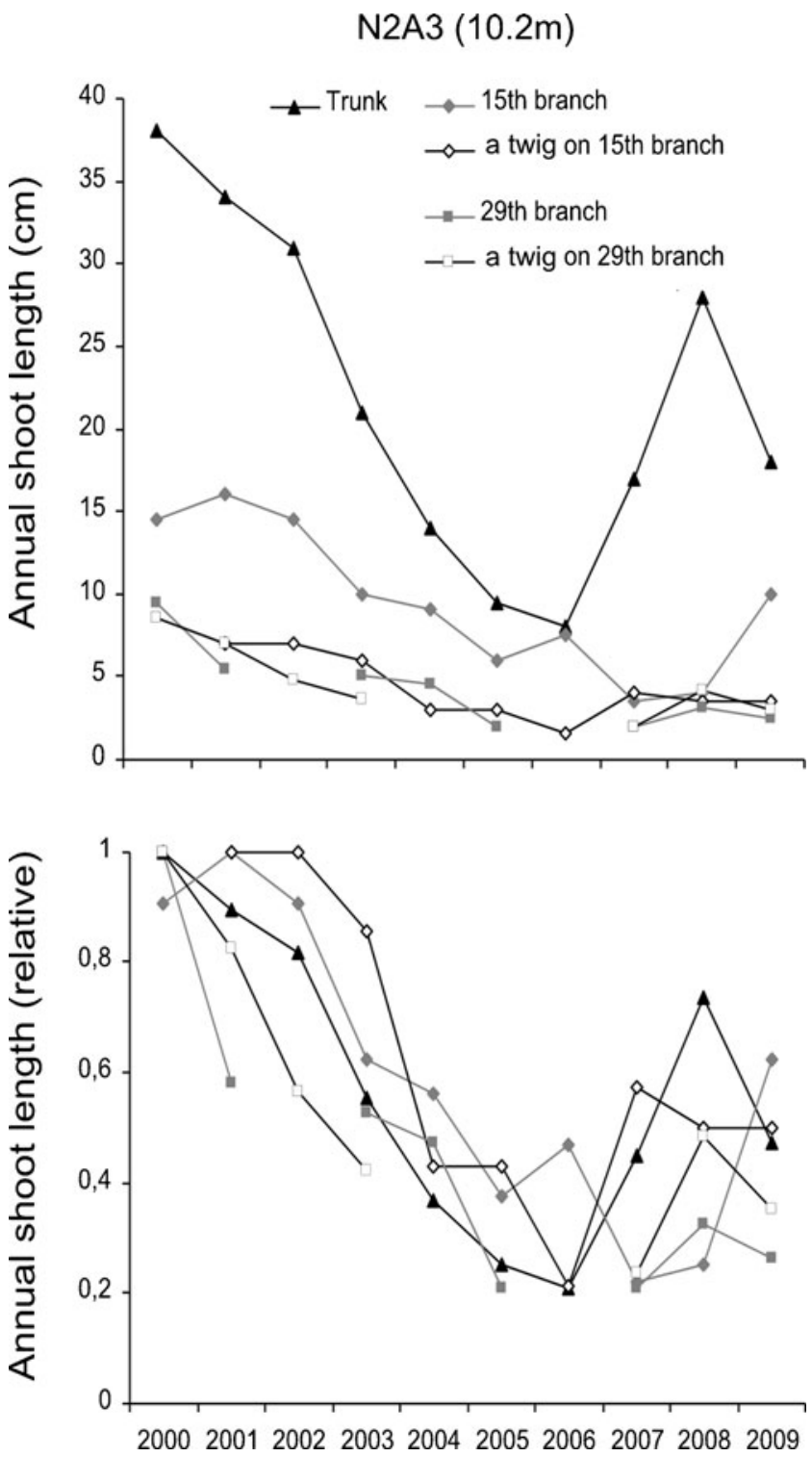

Fig. 5 Intra-crown sensitivity to climate. Annual shoot lengths for the adult tree, according to growth year, along the trunk (black line), two branches (grey lines) and one twig per branch (dashed lines). One branch is in the upper part of the crown (from the 15th branch tier, diamond-shaped symbols) and the second is in the lowest part of the living crown (from the 29th branch tier, square symbols). The relative length (lower graph) used the longest annual shoot in the 2000-2010 period as a reference $(=1)$

they could be compared without any size effect (Fig. 6). Relative trends showed a similar pattern of fluctuations as seen with crown fluctuations (Fig. 5).

\subsection{Tree development and light environment}

Trees under the clear canopy were at all ages taller than those under the closed canopy (Fig. 7). This was due to a break in the height trend for all trees in the clearest environment, except one. This break corresponded to the start of a rapid height increase. Height trends were used instead of trunk annual shoot length trends to highlight this long-term trend rather than some high frequency signal.

\section{Discussion}

4.1 Retrospective analysis: methodological benefits and cost

Two approaches are commonly used to study temporal processes: diachronic (or longitudinal) and synchronic (or transversal) approaches. Diachronic approaches are expected to be more relevant than synchronic approaches, but require long-term monitoring. The greatest advantage of analysing growth retrospectively is that such a process provides a diachronic information by using plants as their own recorder. For example, in dendrochronology (Schweingruber 1996), annual diameter at breast height (DBH) monitoring is replaced by tree ring width measurements on a trunk wood sample. This provides data for dozens or hundreds of years with only one sampling. Avoiding long-term monitoring may reduce study costs and provide results rapidly after measurements begin.

Working on perennial markers provides numerous methodological facilities as the measurements do not change over time. This means that the measurement schedule can be adapted to suit weather conditions and field availability. Also, it is possible to return to the field to complete measurements or focus on a particular point after data analysis.

The retrospective analysis of growth does of course have some costs: mainly the time required to measure the traits selected. Measurement time depends on trait category: external traits (e.g. annual shoot length) are more rapidly measured than internal traits (e.g. tree ring width). Also, measuring internal traits is mainly destructive whereas external traits can be measured without damaging the tree, especially in small trees. Measurement time is also highly dependent upon tree size. In the present study, two field workers were able to measure annual shoot length trend along a $12-\mathrm{m}$ trunk in only a few hours, and measuring a 20 -year-old branch took them only $20 \mathrm{~min}$. These durations should be compared with those required for a stem analysis (Kariuki 2002) or for sapling digitization (Delagrange et al. 2006).

Sampling strategies are not discussed here but can be implemented using entity homologies and the identification of the physiological age of meristems (Barthélémy and Caraglio 2007).

\subsection{Studying forest tree development}

Tree development is a key process for forest managers, ecologists, and large-scale modellers (Schenk 1996; Kelty 
Fig. 6 Between-tree sensitivity to climate. Annual shoot length according to growth year on the main stem of an adult tree (black line), a $2.2 \mathrm{~m}$ juvenile tree (grey line) and a $0.5 \mathrm{~m}$ juvenile tree (dashed grey line). Relative length (lower graph) used the longest annual shoot in the 2000-2009 period as a reference $(=1)$
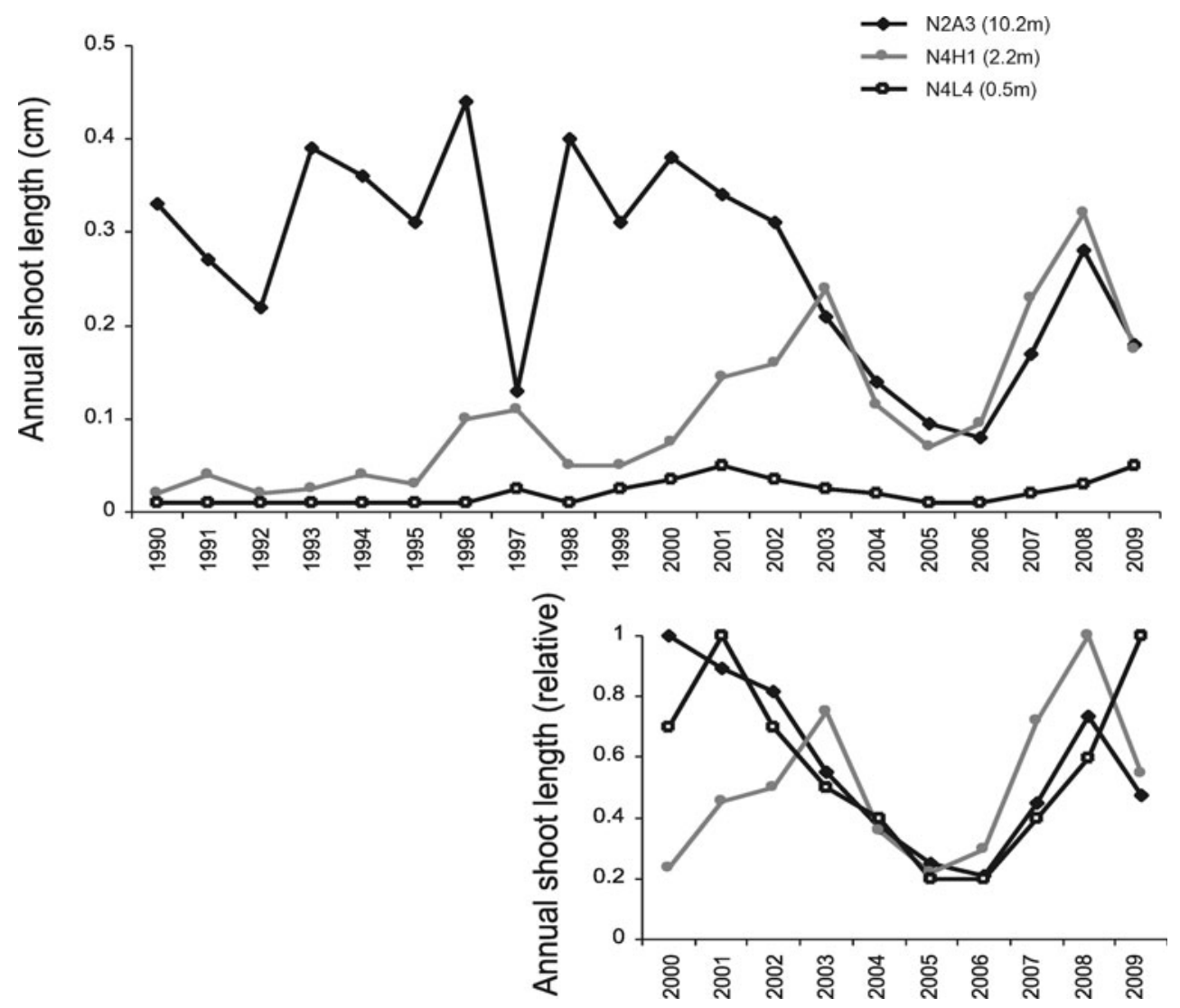

2006; Sato et al. 2007). During ontogeny, it would appear that tree populations show similar trunk increment behaviours in common ontogenetic years (Heuret et al. 2006). This growth trajectory may correspond to the genotype's development programme (Yagi 2009). A retrospective analysis of growth can identify three main kinds of variation around this trajectory: (1) breaks due to the establishment of relay axes replacing dead axes; (2) inter-annual growth fluctuations linked with climate: see following section; (3) speed of the move along the trajectory (i.e. developmental plasticity)

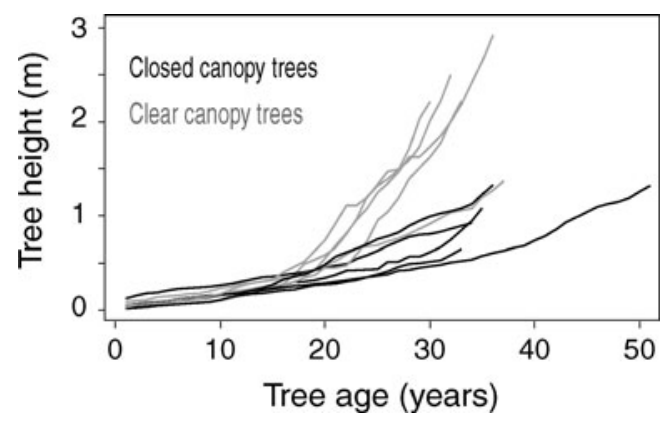

Fig. 7 Tree height in relation to tree age and canopy openness. Tree height trends are given for five trees growing in deep shade (black lines) and five trees growing below a clear canopy (grey lines). At least one tree from each elevation is presented in each group. $N B$ the light environment was characterised during the last year of growth which may change and may be related to resource limitations (Yagi 2009; Barthélémy et al. 2010; Taugourdeau et al. 2011).

This latter point was highlighted in our study by the contrast between height trends in deep shade vs. clear canopy trees (Fig. 7). The break in the trend may be associated with a sudden change in light availability (e.g. forest gap). Between-tree variations under stable light environment conditions may be due to unstudied environmental factors or genetic variations.

At the crown scale, our results suggest that the length of successive annual shoots on different axes accurately indicates the gradual modifications that take place due to the physiological ageing of meristems (Barthélémy and Caraglio 2007). Trunk annual shoot trends may be an indicator of a tree's progression through forest strata while branch annual shoot trends may provide insights into the competitive levels in forest strata.

\subsection{Studying tree sensitivity to climate}

The retrospective analysis of radial growth (i.e. tree rings) is commonly used to establish a record of climatic events (Schweingruber 1996). Tree rings presents several advantages mainly related to the sampling position (trunk base) which integrates whole plant responses, the ease of the 
measurement and the existence of numerous dedicated statistical tools.

Shoot length trends are expected to be less integrative because of the distal position of primary meristems (De Kroon et al. 2009; Kawamura 2010). But shoot length is also known to be sensitive to climate both at trunk level (Chaubert-Pereira et al. 2009; Taugourdeau et al. 2011) and branch level (Thabeet et al. 2009). We found that similar variations occurred in contrasted crown axes. The same synchronous fluctuations where also noted between trees at different developmental stages or located at different elevations. On the other hand, asynchronous fluctuations, e.g. in radial and elongation growth, may be induced by the local environment and by genetics (Chaubert-Pereira et al. 2009).

Forest carbon sequestration is another current issue (Bonan 2008). At present, most methods in this field use $\mathrm{DBH}$ values drawn from inventory data to assess carbon sequestration (Lehtonen et al. 2004) but additional variables may improve this estimation (Cienciala et al. 2006). Here, we provide data corresponding to more than 20 years of silver fir height increments, obtained by retrospective measurements.

\section{Conclusion and perspectives}

Retrospective analyses of architecture provide a methodological framework for assessing the development of perennial plants in relation to their environment. Here, the method was successfully applied to silver firs trees and has the principal advantage of yielding quantitative data covering decades of growth without any destruction of plant material. In the study, the data obtained highlights relevant insights on (1) tree ontogeny by the identification of quantitative ontogenetic trends and their variations with light environment and (2) tree responses to climate by the identification of within crown variations of annual shoot length plasticity that are linked with their architectural position.

Although not discussed here, the authors experienced that growth markers of temperate species are in most cases similar to the markers identified for silver fir (Heuret et al. 2006) but also that other markers such as the number of leaves, the occurrence of growth cycles, the branching pattern or the flowering outbreaks can be of interest for investigating the past history of some species. In any case, a good understanding of tree development is required to avoid misinterpretations of retrospective observations due to specific features such as the polycyclism in pines (Caraglio et al. 2007) oaks (Heuret et al. 2003) and Cedrus species (Sabatier et al. 2003).

Future work on retrospective analysis may focus on root growth (Jourdan and Rey 1997; Charles-Dominique et al.
2009) and on tropical species (Zalamea et al. 2008; Rutishauser et al. 2011).

Acknowledgements The authors are grateful to Pierre CretinMaitenaz, Michäel Guéroult and URFM technical team for their help in collecting field data, to MéteoFrance for providing meteorological data, to François de Coligny, the handling editor and an anonymous reviewer for their helpful comments that led to an improvement in the presentation of this paper.

Funding OT was funded by a French Ministry of Research PhD grant.

\section{References}

Barthélémy D, Caraglio Y (2007) Plant architecture: a dynamic, multilevel and comprehensive approach to plant form, structure and ontogeny. Ann Bot 99:375-407

Barthélémy D, Caraglio Y, Sabatier S (2010) Crown architecture of valuable broadleaved species. In: Spiecker H, Hein S, MakkonenSpiecker K, Thies M (eds) Valuable broadleaved forests in Europe. Leyde, Brill, pp 87-101

Bonan GB (2008) Forests and climate change: forcings, feedbacks, and the climate benefits of forests. Science 320:1444-1449

Bontemps J, Herve J, Dhote J (2009) Long-term changes in forest productivity: a consistent assessment in even-aged stands. For Sci 55:549-564

Cailleret M (2011) Causes fonctionnelles du dépérissement et de la mortalité du sapin pectiné en Provence, $\mathrm{PhD}$ thesis. University of Aix-Marseille III, Avignon, France

Cailleret M, Davi H (2010) Effects of climate on diameter growth of co-occurring Fagus sylvatica and Abies alba along an altitudinal gradient. Trees 25:265-276

Caraglio Y, Rigolot E, Pimont F (2007) Pinus halepensis Mill. Architectural analysis for fuel modelling. Proceedings of the international workshop MEDPINE. pp 43-59

Charles-Dominique T, Mangenet T, Rey H et al (2009) Architectural analysis of root system of sexually vs. vegetatively propagated yam (Dioscorea rotundata Poir.), a tuber monocot. Plant Soil 317:61-77

Chaubert-Pereira F, Caraglio Y, Lavergne C, Guédon Y (2009) Identifying ontogenetic, environmental and individual components of forest tree growth. Ann Bot 104:883-896

Cienciala E, Cerny M, Tatarinov F et al (2006) Biomass functions applicable to Scots pine. Trees 20:483-495

De Kroon H, Visser EJW, Huber H et al (2009) A modular concept of plant foraging behaviour: the interplay between local responses and systemic control. Plant Cell Environ 32:704-712

Delagrange S, Montpied P, Dreyer E et al (2006) Does shade improve light interception efficiency? A comparison among seedlings from shade-tolerant and -intolerant temperate deciduous tree species. New Phytol 172:293-304

Drobyshev I, Overgaard R, Saygin I et al (2010) Masting behaviour and dendrochronology of European beech (Fagus sylvatica L.) in southern Sweden. For Ecol Manag 259:2160-2171

Dulamsuren C, Hauck M, Leuschner HH, Leuschner C (2011) Climate response of tree-ring width in Larix sibirica growing in the drought-stressed forest-steppe ecotone of northern Mongolia. Ann For Sci 68:275-282

Dyer M, Bailey R (1987) A test of 6 methods for estimating true heights from stem analysis data. For Sci 33:3-13

Edelin C (1977) Images de l'architecture des conifères, PhD thesis. Université de Montpellier II, Montpellier 
Everett RG (2008) Dendrochronology-based fire history of mixedconifer forests in the San Jacinto Mountains, California. For Ecol Manag 256:1805-1814

Frazer G, Canham C, Lertzman K (1999) Gap Light Analyzer (GLA): imaging software to extract canopy structure and gap light transmission indices from true-colour fisheye photographs, user's manual and program documentation. Simon Fraser University, Burnaby

Godin C, Caraglio Y (1998) A multiscale model of plant topological structures. J Theor Biol 191:1-46

Hallé F, Martin R (1968) Etude de la croissance rythmique chez l'Hévéa (Hevea brasiliensis Müll.-Arg. Euphorbiacées-Crotonoïdées). Adansonia 8:475-503

Heuret P, Guédon Y, Guérard N, Barthélémy D (2003) Analysing branching pattern in plantations of young red oak trees (Quercus rubra L., Fagaceae). Ann Bot 91:479-492

Heuret P, Meredieu C, Coudurier T et al (2006) Ontogenetic trends in the morphological features of main stem annual shoots of Pinus pinaster (Pinaceae). Am J Bot 93:1577-1587

Jourdan C, Rey H (1997) Architecture and development of the oil-palm (Elaeis guineensis Jacq) root system. Plant Soil 189:33-48

Kariuki M (2002) Height estimation in complete stem analysis using annual radial growth measurements. Forestry 75:63-74

Kawamura K (2010) A conceptual framework for the study of modular responses to local environmental heterogeneity within the plant crown and a review of related concepts. Ecol Res 25:733-744

Kelty M (2006) The role of species mixtures in plantation forestry. For Ecol Manag 233:195-204

Lehtonen A, Makipaa R, Heikkinen J et al (2004) Biomass expansion factors (BEFs) for Scots pine, Norway spruce and birch according to stand age for boreal forests. For Ecol Manag 188:211-224

Linares JC, Camarero JJ, Carreira JA (2010) Competition modulates the adaptation capacity of forests to climatic stress: insights from recent growth decline and death in relict stands of the Mediterranean fir Abies pinsapo. J Ecology 98:592-603

Metsaranta J, Lieffers V (2009) Using dendrochronology to obtain annual data for modelling stand development: a supplement to permanent sample plots. Forestry 82:163-173

Pradal C, Dufour-Kowalski S, Boudon F et al (2008) OpenAlea: a visual programming and component-based software platform for plant modelling. Funct Plant Biol 35:751-760

Rey H, Godin C, Guédon Y (1997) Vers une représentation formelle des plantes. In: Bouchon J, De Reffye P, Barthélémy D (eds)
Modélisation et simulation de l'architecture des végétaux, INRA éditions. INRA éditions, Paris, pp 139-174

Richardson S, Smale M, Hurst J et al (2009) Large-tree growth and mortality rates in forests of the central North Island, New Zealand. New Zealand J Ecol 33:208-215

Robakowski P, Wyka T, Samardakiewicz S, Kierzkowski D (2004) Growth, photosynthesis, and needle structure of silver fir (Abies alba Mill.) seedlings under different canopies. For Ecol Manag 201:211-227

Rutishauser E, Barthélémy D, Blanc L, Nicolini E (2011) Crown fragmentation assessment in tropical trees: method, insights and perspectives. For Ecol Manag 261:400-407

Sabatier S, Baradat Ph, Barthélémy D (2003) Intra- and interspecific variations of polycyclism in young trees of Cedrus atlantica (Endl.) Manetti ex. Carrière and Cedrus libani A. Rich (Pinaceae). Ann For Sci 60:19-29

Sato H, Itoh A, Kohyama T (2007) SEIB-DGVM: a new dynamic global vegetation model using a spatially explicit individualbased approach. Ecol Modell 200:279-307

Saulnier M, Edouard JL, Corona C, Guibal F (2011) Climate/growth relationships in a Pinus cembra high-elevation network in the Southern French Alps. Ann For Sci 68:189-200

Schenk HJ (1996) Modeling the effects of temperature on growth and persistence of tree species: a critical review of tree population models. Ecol Modell 92:1-32

Schweingruber FH (1996) Tree rings and environment: dendroecology. Paul Haupt AG Bern, Switzerland

Stoffel M, Bollschweiler M (2008) Tree-ring analysis in natural hazards research - an overview. Nat Hazard Earth Sys 8:187-202

Taugourdeau O, Chaubert-Pereira F, Sabatier S, Guédon Y (2011) Deciphering the developmental plasticity of walnut saplings in relation to climatic factors and light environment. J Exp Bot 62:5283-5296

Thabeet A, Vennetier M, Gadbin-Henry C et al (2009) Response of Pinus sylvestris L. to recent climatic events in the French Mediterranean region. Trees 23:843-853

Yagi T (2009) Ontogenetic strategy shift in sapling architecture of Fagus crenata in the dense understorey vegetation of canopy gaps created by selective cutting. Can J For Res 39:1186-1196

Zalamea P, Stevenson P, Madrinan S et al (2008) Growth pattern and age determination for Cecropia sciadophylla (Urticaceae). Am J Bot 95:263-271 